\title{
Metassíntese qualitativa sobre a manutenção do espanhol como língua de herança em contexto brasileiro.
}

\author{
Érica Fernandes Borges ${ }^{1}$ \\ Idalena Oliveira Chaves ${ }^{2}$
}

\begin{abstract}
Resumo: Nos últimos anos, a discussão sobre a manutenção do espanhol como língua de herança, doravante ELH, tem sido alvo de crescente debate na Linguística Aplicada (MONTRUL, 2012; VALDÉS, 2001; WONG FILLMORE, 2000; MORENO FERNÁNDEZ, 2005). Podemos afirmar que, de forma geral, os estudos sobre a manutenção do ELH estão voltados para as áreas da Linguística e da Sociolinguística e buscam identificar as razões pelas quais tais fenômenos ocorrem. A maioria das pesquisas sobre o tema em questão foram realizadas nos Estados Unidos, país que abriga um grande número de hispanofalantes, assim como o Brasil. Nesse sentido, este estudo, que apresenta resultados preliminares de uma pesquisa mais ampla em andamento, tem como objetivo realizar um levantamento de estudos sobre a manutenção do ELH no Brasil por meio de uma pesquisa bibliográfica nos portais de periódicos Capes e Scielo, mapeando, de certa forma, a produção acadêmica brasileira sobre o tema em questão. Com os resultados obtidos, espera-se que outros pesquisadores de ELH no Brasil possam se beneficiar deste estudo para justificar a importância de pesquisas sobre a manutenção do espanhol como língua de herança em contexto brasileiro.
\end{abstract}

Palavras-chave: Imigração; Língua de herança; Espanhol como língua de herança no Brasil.

Todas as línguas são a expressão de uma identidade coletiva e de uma maneira distinta de apreender e descrever a realidade, pelo que devem poder beneficiar das condições necessárias ao seu desenvolvimento em todas as funções.

(Declaração Universal dos Direitos Linguísticos, 1996, art. $7^{\circ}$ )

A herança imaterial não é uma questão de saudosismo da terra natal, nem se trata de uma atividade romântica de quem se vê distante de sua família. Mas é uma questão de saúde existencial para a condição de estrangeiro.

(Heath, 2017, p.10)

1 Graduada em Letras Português/Espanhol pela UNIG - Campus V, especialista em Estudos Linguísticos e Literários pelo Centro Universitário São José de Itaperuna, Mestranda em Estudos Linguísticos pela Universidade Federal de Viçosa, linha de pesquisa Linguística Aplicada: formação de professores de linguas. Professora Docente I da disciplina Espanhol na SEEDUC-RJ. ericaborges78@hotmail.com

2 Professora- Adjunta do Departamento de Letras da Universidade Federal de Viçosa, coordenadora do Curso de Extensão em Português para Estrangeiros (CELIPE), do Programa Idiomas Sem Fronteiras (ISF-Português), e do posto aplicador do Exame Celpe-bras. Também é vinculada ao programa de pós-graduação em Letras, na linha de pesquisa "Linguística Aplicada: Formação de Professores e Ensino e Aprendizagem de Linguas". Possui doutorado em Linguística teórica e descritiva (2013), mestrado em Estudos Linguísticos (2000) e graduação em Letras pela Universidade Federal de Minas Gerais(1996).idalena@ufv.br 


\section{Introdução}

O Brasil pode ser considerado um país de imigração desde a chegada dos portugueses, quando os povos nativos que aqui viviam sofreram incontáveis abusos e violações de seus direitos. Em seguida, milhões de pessoas de diferentes etnias do continente africano foram escravizadas e forçadas a virem para o Brasil. Com o fim da escravidão, políticas governamentais atraíram uma série de imigrantes, de diferentes nacionalidades, com o intuito de substituir a mão de obra escrava.

No cenário brasileiro atual, os hispânicos ocupam um lugar de destaque no movimento migratório por vários motivos, entre eles o comércio, a indústria, a política, a cultura, a arte, a literatura, decorrentes das fortes ligações sempre presentes na história, porém estreitadas ou reforçadas após acordos internacionais como o MERCOSUL e a XV Cúpula IberoAmericana, realizada na Espanha, em Salamanca, no ano de 2005.

Segundo matéria publicada no jornal espanhol El País, em abril de $2017^{3}$, os espanhóis encontram-se entre os principais investidores estrangeiros no Brasil, possuindo empresas na área de telecomunicações, energia, transporte e finanças. Esse intercâmbio econômico favorece também ligações culturais promovidas pelo Ministério de Assuntos Exteriores da Espanha vinculado ao Instituto Cervantes.

Além da presença e de investimento espanhol no setor econômico e seus reflexos na economia brasileira, há também (um)a presença cultural no espaço brasileiro como se constata em:

Lo que en un pasado no muy lejano formaba parte de ámbitos reducidos, hoy es habitual: cine, literatura y otras manifestaciones culturales hispánicas ocupan cada vez más espacio y su presencia es más asidua en los medios de comunicación brasileños, del mismo modo que en las actividades relacionadas con nuestra cultura (española) gozan cada día de más amplia aceptación. (CONSEJERÍA DE EDUCACIÓN y CIENCIA, 1998, p. 9) ${ }^{4}$

3 Brasil e Espanha: uma nova colaboração entre velhos amigos. Disponivel em: https://brasil.elpais.com/brasil/2017/04/22/ actualidad/1492814836 462443.html. Acesso em: 22 jul. 2020.

$4 \mathrm{O}$ que em um passado muito distante formava parte de âmbitos reduzidos, hoje é habitual: cinema, literatura e outras manifestações culturais hispânicas ocupam cada vez mais espaço e mais representação nos meios de comunicação brasileiros, do mesmo modo que nas atividades relacionadas com nossa cultura (espanhola) desfrutam de uma aceitação mais ampla a cada dia. 
Ademais, o estreitamento das relações entre Brasil e demais países da América Latina aumentou o fluxo imigratório entre países hispanofalantes que fazem fronteira com o país. Os números de peruanos, colombianos, argentinos, uruguaios, venezuelanos vêm aumentando. Com a crise econômica, política e social vivida na Venezuela, nos últimos anos, esses números tendem a crescer.

Considerando o cenário apresentado, percebe-se a existência da necessidade de pensarmos o lugar ocupado pela língua de herança, doravante $\mathrm{LH}$, na vida das famílias hispânicas que vivem no Brasil. Para Valdés (2001), falantes de herança são pessoas que aprenderam a língua em seu país de origem como primeira língua (L1), ou que têm alguma relação familiar com ela, por exemplo, falantes de segunda e terceira geração. Língua é identidade. Falar uma língua é sentir-se parte da comunidade, pois ela traz consigo características culturais que demonstram como um grupo se manifesta, ou seja, a cultura de uma determinada comunidade de fala.

Diante do fato de haver uma quantidade significativa de famílias hispano descendentes vivendo no Brasil, surgiu o seguinte questionamento: e quanto à língua de herança? Tem-se realizado estudos a respeito do tema? Essa é a questão que este artigo busca responder por meio de uma pesquisa bibliográfica nos portais de periódicos Capes e Scielo.

\section{Referencial teórico}

Antes de iniciar a seção, considera-se necessário esclarecer algumas definições e conceitos importantes que serão abordados no estudo a fim de melhor compreendê-lo.

\section{Imigrante, Refugiado e Asilado Político}

Costuma-se, no senso comum, haver certa confusão entre os termos 1) imigrante, 2) refugiado, 3) asilado político pelo fato de ambos se deslocarem. Embora os indivíduos nessas situações tenham alguma semelhança, a de não estarem em seu país de origem, as razões pelas quais se deslocam e pedem solicitação de visto, asilo ou refúgio são diferentes.

$$
\text { Gláuks: Revista de Letras e Artes-jan/jun. } 2020 \text { - Vol. 20, } N^{o} 1
$$


É considerada imigrante uma pessoa que se desloca, de maneira voluntária, de seu país de origem para outro, por motivos variados, com a intenção de se estabelecer por algum tempo no país escolhido. Segundo a Lei de Migração, Lei no 13. 445/2017, de 24 de maio de 2017, o imigrante é a "pessoa nacional de outro país ou apátrida que trabalha ou reside e se estabelece temporária ou definitivamente no Brasil"5.

É considerada asilada política a pessoa que esteja sendo perseguida por motivos políticos em seu país de origem e que não esteja aguardando julgamento sob acusação de ter cometido crime comum. É importante salientar que cabe ao Estado a decisão sobre o aceite ou não da solicitação de asilo, ainda que o solicitante cumpra com os requisitos mencionados.

É considerado refugiado todo aquele que está fora de seu país de origem devido "a temores de perseguição relacionados a questões de raça, religião, nacionalidade, pertencimento a um determinado grupo social ou opinião política", assim como "devido à grave e generalizada violação dos direitos humanos e conflitos armados" (UNHCR ACNUR, 2019). Os refugiados costumam ser confundidos com os asilados pelo fato de ambos deslocarem-se em virtude de algum tipo de perseguição. Nesse sentido, cabe ressaltar que a grande diferença entre "refúgio" e "asilo" é que, no caso dos refugiados, não cabe ao Estado para o qual imigram decidir, de forma política, sobre a acolhida ou não aos indivíduos nessa situação, pois a regulamentação internacional referente ao refúgio baseia-se, sobretudo, na Convenção de Genebra de 1951, que garante aos refugiados o direito de não serem expulsos ou deportados a seus países enquanto permanecerem os riscos a sua vida ou liberdade.

\section{Língua Materna e Língua de Herança}

Considera-se como língua materna (LM) ou primeira língua (L1) aquela naturalmente adquirida por meio da interação com o meio social, sem intervenção pedagógica e sem uma reflexão linguística consciente. Geralmente, é a língua majoritária do país no qual se vive, usada oficialmente como língua de instrução nas escolas.

5 Lei $n^{\circ} 13.445 / 2017$, de 24 de maio de 2017. Disponível em: http://www.planalto.gov.br/ccivil 03/ato2015-2018/2017/lei/l13445.htm. Acesso em: 22 jul. 2020. 
Para Lico e Boruchowski (2016), "uma língua de herança é aquela utilizada com restrições (limitada a um grupo social ou ao ambiente familiar) e que convive com outra(s) língua(s) que circula(m) em outros setores, instituições e mídia da sociedade em que se vive" (LICO; BORUCHOWSKI, 2016, p. 9).

Conforme citado anteriormente, Valdés (2001) considera como falantes de herança as pessoas que aprenderam a língua em seu país de origem como primeira língua (L1), ou que têm alguma relação familiar com ela, por exemplo, falantes de segunda e terceira geração. Esses falantes podem apresentar diferentes níveis de compreensão e habilidade na língua de herança, desde apenas entenderem a língua, até demonstrarem domínio da oralidade, compreensão, leitura e escrita.

Uma das pesquisadoras sobre a língua de herança, em contexto brasileiro, Alvarez, a define como aquela "[...] aprendida em seio familiar desde tenra idade, pelo que, na maioria dos casos, é a primeira língua a ser adquirida pela criança” (ALVAREZ, 2016, p. 64). A autora ainda afirma que a LH corresponde a uma língua minoritária e que, embora adquirida naturalmente desde a primeira infância, não é a língua dominante do falante de herança (ALVAREZ, 2016).

Para Montrul (2012) uma das principais diferenças entre um falante de herança e um falante nativo é a falta de desenvolvimento de competências gramaticais devido à escassez de input, visto que quase todo estímulo que o falante recebe na língua de herança provém de contextos familiares ou pouco formais. Para Valdés (2001, p. 3), os falantes de herança formam um grupo muito heterogêneo, pois possuem níveis de competência variados, o que resulta na dificuldade de delimitação.

Considerando-se que todos os falantes de herança são, independente do seu domínio na língua de herança, até certo ponto, bilíngues na língua de herança e na língua dominante da sociedade na qual vivem, entende-se que o bilinguismo seja uma característica do grupo em questão. A seguir, passa-se a alguns esclarecimentos em torno do termo bilinguismo.

\section{Bilinguismo}

Existem diferentes definições sobre o conceito de bilinguismo/multilinguismo, entretanto, de forma geral, considera-se bilíngue aquele que possui conhecimento e domínio, 
em diferentes níveis, de duas ou mais línguas (MONTRUL, 2008, p. 17). De maneira semelhante ao caso do nível de proficiência do falante de herança, o nível do falante bilíngue é mais difícil de delimitar, visto os diferentes níveis de competência nas línguas. Segundo Valdés (2001, p. 4) e Montrul (2008, p. 18), a possibilidade de que uma pessoa bilíngue tenha o mesmo nível de proficiência nas línguas é pouco realista, pois sempre existirá uma língua mais "forte" e outra mais "fraca", a depender de vários fatores.

Para Montrul (2008, p. 19), existem dois fatores que mais influenciam o nível de domínio de uma língua, a idade e a ordem de aquisição. Alguns falantes de herança vivem, desde o nascimento, em contexto no qual coexistem a língua de herança e a língua majoritária. Estes são considerados, por essa razão, bilíngues simultâneos. Outros podem ter crescido em cenário monolíngue até a primeira infância e tornaram-se bilíngues ao migrarem para outro país, de língua diferente daquele no qual viviam até o momento, sendo considerados, nesse caso, bilingues sequenciais (MONTRUL, 2012, p. 2). Classificados como bilingues simultâneos ou sequenciais, um fator em comum entre esses falantes é que a LH tende a ocupar o lugar de língua "fraca" quando alcançam a idade adulta.

Visto que "o bilinguismo é uma condição dinâmica" (VALDÉS, 2001, p. 6), o nível de proficiência de um falante pode variar de acordo com o contexto no qual está inserido. Adaptamos o gráfico de Montrul (2012, p.7) para exemplificar uma possível variação nos níveis de domínio das línguas de um falante de língua de herança (LH) e de língua dominante (LD) ${ }^{6}$ ao longo de sua vida.

6 Neste trabalho, as autoras usam os termos "língua majoritária" e "língua dominante" como sinônimos. 
Gráfico 1 - A variação do domínio LH/LD

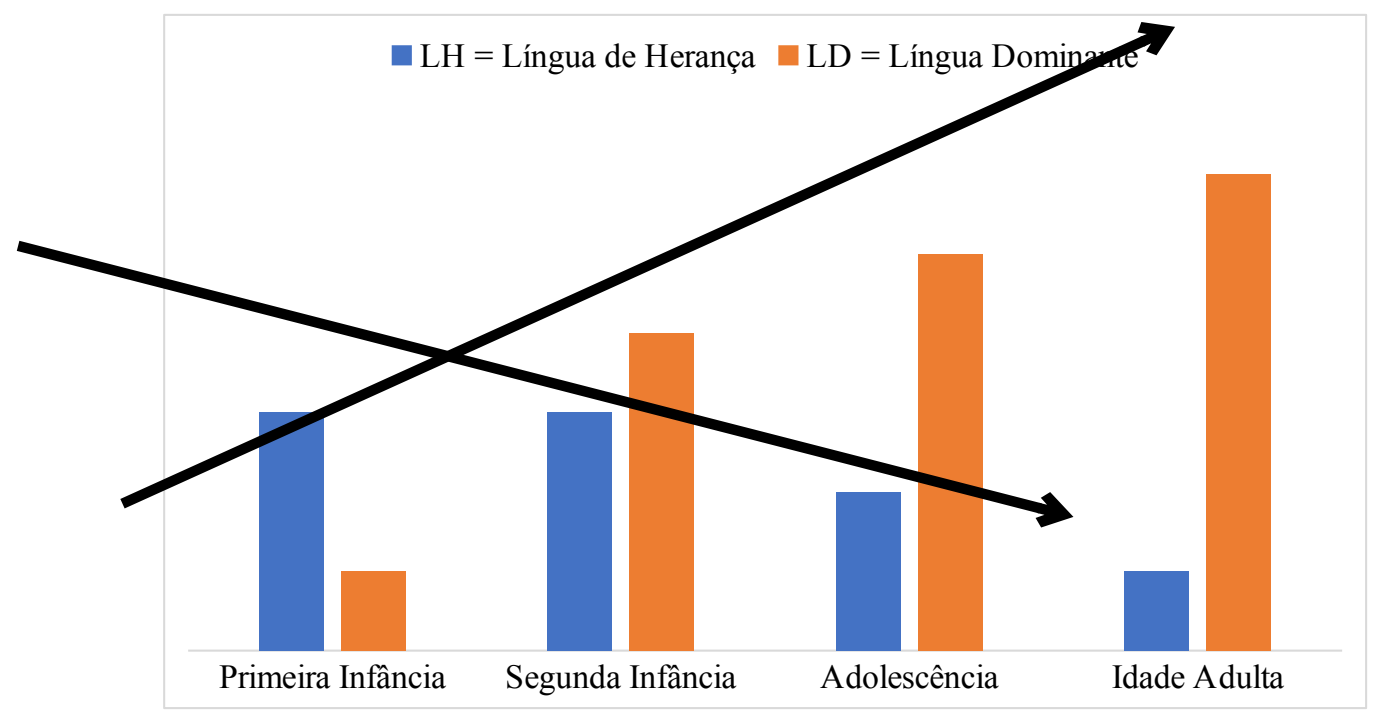

Fonte: Adaptado de MONTRUL (2012, p. 7).

Ao analisarmos os dados obtidos com a leitura do gráfico de Montrul (2012, p.7), podemos constatar que o domínio da LH tende a uma redução à medida que o falante cresce $\mathrm{e}$ começa a interagir com o contexto social da língua majoritária, isto é, a língua dominante (LD), enquanto que sua competência na língua dominante tende a aumentar.

O desejo de integração, a escolarização na língua dominante/majoritária da sociedade e o baixo input na LH são fatores determinantes na falta de competência dos falantes de 
herança na língua familiar, o que pode fazer com que tais falantes sintam-se mais confortáveis ao falarem a língua majoritária (MONTRUL, 2008).

Destaca-se que algumas famílias de imigrantes decidem abandonar a LH para distanciarem-se psicologicamente de seu passado, possivelmente por terem sofrido traumas em seu país de origem ou como forma de acelerar o processo de integração familiar no país escolhido. Wong Fillmore (2000, p. 208) afirma que jovens imigrantes tendem a perder a língua de herança por questões internas e externas relacionadas à manutenção da LH. De um lado, o desejo de integração, inclusão social e a necessidade de comunicar-se com os outros e, por outro lado, fatores sociopolíticos que circulam na sociedade de acolhimento, como preconceitos e discriminações, pelo fato de falarem uma língua diferente e pertencerem a uma cultura diferente (WONG FILLMORE, 2000, p. 208).

Considerando ideologia linguística como qualquer conjunto de crenças ou sentimentos sobre as línguas usadas no mundo social, indivíduos que têm contato com uma língua no ambiente familiar (falantes de herança) e convivem em um contexto no qual a língua majoritária é diferente daquela usada em casa, geralmente, estão expostos a várias situações que podem gerar dificuldades para famílias que vivem entre a língua de herança e a língua dominante.

Uma dessas situações ocorre quando a criança ou o jovem entende a língua minoritária, mas só responde na majoritária. Existem muitas explicações para a ocorrência desse fenômeno, sendo uma delas "sobre o valor e o status da língua de herança na sociedade em que se vive" (LICO; BORUCHOWSKI, 2016, p. 17). Ou seja, uma ideologia a respeito da língua majoritária possivelmente como superior às línguas de herança.

Ainda segundo as autoras citadas anteriormente, outro exemplo que pode gerar dificuldades quanto à manutenção da língua de herança é a concepção de muitos pais sobre a necessidade de falar somente a língua majoritária em contexto familiar, a fim de colaborar com o bom desempenho escolar dos filhos, uma vez que a língua da escolarização é a "dominante".

Fatores como 1) o valor e o status da língua de herança na sociedade em que se vive e 2) a concepção de muitos pais sobre a necessidade de falar somente a língua majoritária em contexto familiar, a fim de colaborar com o bom desempenho escolar dos filhos, podem levar esses falantes de herança a crises de identidade, assim como a revisão dos valores que eles 
mesmos atribuem à língua e à cultura familiar, optando por priorizar a língua majoritária e até mesmo rejeitar a língua de herança.

Outro aspecto levantado no estudo de Moreno Fernandez (2005, p. 178) é sobre a construção da identidade cultural e linguística dos falantes de língua de herança, que ocorre de maneira diferente dos falantes monolíngues, visto que falantes de herança têm acesso a dois ou mais sistemas linguísticos e conceituais, ou seja, mais recursos para negociar e comunicar os diferentes aspectos de sua identidade. $\mathrm{O}$ autor define a relação entre língua e cultura da seguinte maneira:

Las lenguas no son solo portadoras de unas formas y unos atributos lingüísticos determinados, sino que también son capaces de transmitir significados o connotaciones sociales, además de valores sentimentales. Las normas y marcas culturales de un grupo se transmiten o enfatizan por medio de la lengua (MORENO FERNÁNDEZ, 2005, p. 178). ${ }^{7}$

Entendemos que um estudo sobre a manutenção de uma língua de herança deve tratar tanto de uma investigação sobre aquisição, aprendizagem ou de resultados relacionados à proficiência linguística como da transmissão de um legado cultural, quanto da língua como fator sociocultural, o que se constata em:

(...) A própria noção de língua de herança (LH) é sociocultural uma vez que é definida em termos do grupo das pessoas que a falam. As línguas de herança também cumprem uma função sociocultural, tanto como meio de comunicação como modo de identificar e transformar grupos socioculturais. (HE, 2012, p. 66)

Podemos afirmar que, de forma geral, os estudos sobre a manutenção/perda do espanhol como LH estão voltados para as áreas da Linguística e da Sociolinguística e buscam identificar as razões pelas quais tais fenômenos ocorrem. A maioria dos estudos sobre o tema em questão foram realizados nos Estados Unidos, país que abriga um grande número de hispanofalantes, razão pela qual empreendemos este estudo a fim de averiguar a existência de pesquisas sobre a manutenção do ELH no Brasil.

7 Tradução livre: As línguas não são apenas portadoras de formas e atributos linguísticos determinados, como também capazes de transmitir significados ou conotações sociais, além de valores sentimentais. As características e marcas cultuais de um grupo transmitem-se ou enfatizam-se por meio da língua. 


\section{Metodologia}

Com o intuito de obter uma medição precisa a respeito dos estudos sobre a manutenção do espanhol como língua de herança em contexto brasileiro, este estudo classifica-se como uma pesquisa qualitativa exploratória que se utilizará do levantamento bibliográfico para sua realização.

Optamos pelo levantamento bibliográfico por considerá-lo mais adequado para alcançarmos nosso objetivo. Galvão (2010, p. 01) afirma que:

(...) realizar um levantamento bibliográfico é se potencializar intelectualmente com o conhecimento coletivo, para se ir além. É munir-se com condições cognitivas melhores, a fim de: evitar a duplicação de pesquisas, ou quando for de interesse, reaproveitar e replicar pesquisas em diferentes escalas e contextos; observar possíveis falhas nos estudos realizados; conhecer os recursos necessários para a construção de um estudo com características específicas; desenvolver estudos que cubram lacunas na literatura trazendo real contribuição para a área de conhecimento; propor temas, problemas, hipóteses e metodologias inovadores de pesquisa; otimizar recursos disponíveis em prol da sociedade, do campo científico, das instituições e dos governos que subsidiam a ciência. (GALVÃO, 2010, p.01)

Partindo das considerações de Galvão (2010) no que diz respeito à proposição de temas inovadores de pesquisas, verificamos como está a discussão sobre o tema "língua de herança" - sobretudo o ELH - no Brasil, contribuindo, dessa forma, com um levantamento indicativo de estudos sobre a manutenção do espanhol como língua de herança em contexto brasileiro.

Escolhemos duas bases de dados para o levantamento bibliográfico: os portais de periódicos Capes e Scielo. Durante o mapeamento sobre o tema "espanhol como língua de herança", optamos por trabalhar com artigos com o seguinte perfil: 1) que possuíssem o termo "língua de herança" ou "espanhol como língua de herança" no título, no resumo ou nas palavras-chave; 2) que fossem de autoras ou autores brasileiros; 3) que tivessem sido escritos em língua portuguesa e 4) que tivessem sido divulgados em periódicos brasileiros. Não houve delimitação de tempo. 
Foram feitos acessos via internet ao portal de periódicos da Capes e do Scielo. Cada portal foi acessado apenas uma vez, sendo o da Capes no dia 20 de novembro de 2019 e o portal Scielo, 21 de novembro de 2019. Na página do portal Capes, escolhemos a seção "periódicos" e digitamos, na busca avançada, os termos "espanhol" e "língua herança", aparecendo, então, 39 trabalhos relacionados. Por consequência da delimitação da pesquisa, foram excluídos todos os trabalhos que não se enquadravam nos critérios do perfil de seleção do corpus da pesquisa, restando apenas um artigo dentro do perfil disponível nesse portal.

Como mencionado anteriormente, o acesso ao portal Scielo foi feito no dia 21 de novembro de 2019, escolhemos a opção "pesquisa por artigos". No campo "pesquisar", foram selecionadas as palavras "língua de herança". Em seguida, filtramos por trabalhos da área da Linguística, escritos em português e publicados no Brasil. Dois artigos foram encontrados.

É importante ressaltar que este levantamento bibliográfico não pretendia levantar todos os textos publicados sobre língua de herança, mas encontrar informações precisas a respeito da existência de estudos sobre a manutenção do espanhol como língua de herança em contexto brasileiro.

Ressaltamos, ainda, que os resultados obtidos levam em consideração apenas aqueles artigos que apresentam os termos "espanhol" e "língua herança" no título e no resumo. Talvez existam textos com uma perspectiva semelhante à desse campo de estudo, mas pode ser que não estejam disponíveis na base de dados a partir dos critérios de seleção utilizados.

\section{Discussão dos resultados}

Finalizado o levantamento, obtivemos o total de três artigos, o que, a priori, indica um baixo número de trabalhos sobre o assunto. A seguir, disponibilizamos as informações preliminares sobre os resultados. 
Quadro 2 - Dados coletados

\begin{tabular}{|c|c|c|c|c|c|}
\hline Artigo & Plataforma & $\begin{array}{l}\text { Autor } \\
\text { (es) }\end{array}$ & $\begin{array}{c}\text { Ano } \\
\text { de } \\
\text { publicação }\end{array}$ & Objetivo & Método \\
\hline $\begin{array}{l}\text { Contribuições } \\
\text { da } \\
\text { sociolinguística } \\
\text { ao ensino do } \\
\text { português em } \\
\text { comunidades } \\
\text { bilíngues do } \\
\text { norte do } \\
\text { Uruguai. }\end{array}$ & Capes & $\begin{array}{l}\text { Ana } \\
\text { Maria } \\
\text { Carvalho }\end{array}$ & 2010 & $\begin{array}{l}\text { Contribuir ao } \\
\text { desenvolvimento } \\
\text { de uma } \\
\text { pedagogia } \\
\text { sensível às } \\
\text { diferenças } \\
\text { sociolinguísticas } \\
\text { e culturais dos } \\
\text { alunos residentes } \\
\text { na fronteira. }\end{array}$ & $\begin{array}{l}\text { Não } \\
\text { informado. }\end{array}$ \\
\hline $\begin{array}{l}\text { "Aqui somos } \\
\text { protegidos pelas } \\
\text { nossas quatro } \\
\text { paredes. Aqui } \\
\text { nós falamos } \\
\text { alemão": } \\
\text { histórias de } \\
\text { letramentos } \\
\text { interculturais no } \\
\text { Vale do Itajaí, } \\
\text { SC }\end{array}$ & Scielo & $\begin{array}{l}\text { Maristela } \\
\text { Pereira } \\
\text { Fritzen; } \\
\text { Luana } \\
\text { Ewald. }\end{array}$ & 2013 & $\begin{array}{l}\text { Refletir sobre as } \\
\text { práticas sociais } \\
\text { de leitura e de } \\
\text { escrita em um } \\
\text { cenário de } \\
\text { imigração alemã, } \\
\text { no Médio Vale do } \\
\text { Itajaí, SC. }\end{array}$ & $\begin{array}{l}\text { Entrevista } \\
\text { narrativa. }\end{array}$ \\
\hline $\begin{array}{l}\text { Ich spreche } \\
\text { anders, aber } \\
\text { das ist auch } \\
\text { deutsch: línguas } \\
\text { em conflito em } \\
\text { uma escola rural } \\
\text { localizada em } \\
\text { zona de } \\
\text { imigração no } \\
\text { sul do Brasil }\end{array}$ & Scielo & $\begin{array}{l}\text { Maristela } \\
\text { Pereira } \\
\text { Fritzen }\end{array}$ & 2008 & $\begin{array}{l}\text { Problematizar a } \\
\text { situação de } \\
\text { contato/conflito } \\
\text { linguístico } \\
\text { existente na } \\
\text { região alvo da } \\
\text { pesquisa e sua } \\
\text { interface com } \\
\text { questões de } \\
\text { identidades } \\
\text { construídas nos } \\
\text { discursos } \\
\text { hegemônicos. }\end{array}$ & $\begin{array}{l}\text { Etnografia. } \\
\text { Não } \\
\text { informa os } \\
\text { métodos. }\end{array}$ \\
\hline
\end{tabular}

Fonte: Elaborado pelas autoras.

No estudo "Contribuições da sociolinguística ao ensino de português em comunidades bilíngues no norte do Uruguai”, encontrado no portal Capes, a autora discute alguns fatores sociolinguísticos relevantes ao ensino de português nas comunidades bilíngues 
em espanhol e português no norte do Uruguai, destacando características relevantes ao repertório linguístico dessas comunidades, tais como o bilinguismo e os padrões de variação interna. Após a discussão inicial, a autora explora algumas sugestões pedagógicas oferecidas no campo do ensino de Língua Materna e de Língua de herança.

No portal Scielo, dois estudos foram identificados de acordo com os critérios de seleção estabelecidos. No primeiro, “Aqui somos protegidos pelas nossas quatro paredes. Aqui nós falamos alemão": histórias de letramentos interculturais no Vale do Itajaí, SC, as autoras refletem sobre a manutenção do alemão como língua de herança por meio de uma pesquisa interpretativista. O segundo, "Ich spreche anders, aber das ist auch deutsch: línguas em conflito em uma escola rural localizada em zona de imigração no sul do Brasil", resulta de uma pesquisa etnográfica e focaliza o conflito linguístico presente em uma escola rural localizada numa comunidade bilíngue/multilíngue, em zona de imigração alemã, no sul do país, na qual as crianças aprendem em casa a língua de herança, alemão, empregada em âmbito familiar e social.

\section{Considerações finais}

Diante do exposto por meio deste levantamento, percebe-se que existe uma carência relacionada aos trabalhos sobre a manutenção do ELH no Brasil, pois, de acordo com os critérios estabelecidos, foram encontrados apenas três trabalhos e nenhum deles voltado especificamente para o tema em questão.

Constatamos que estudos sobre a manutenção do ELH ainda são escassos no Brasil, embora haja grande número de imigrantes hispânicos vivendo em território brasileiro, o que nos leva a considerar a importância da reflexão sobre a necessidade de pesquisas relacionadas ao tema, sobretudo, devido ao atual contexto imigratório do país.

Teis (2007, p.75) enfatiza a necessidade de "respeitar e preservar o uso da língua materna das minorias étnicas como meio de manutenção da dignidade e do respeito próprio do indivíduo (...)". Devemos considerar, portanto, que a população brasileira é composta por uma sociedade plural, por esse motivo faz-se necessário refletir que os fluxos de imigrantes

Gláuks: Revista de Letras e Artes-jan/jun. 2020 - Vol. 20, $N^{o} 1$ 
assinalam uma dimensão de interação entre pessoas de culturas distintas. Trabalhar em função da manutenção das identidades de pessoas desvalorizadas ou invisibilizadas em nossa sociedade é possibilitar a integração, além de promover a igualdade e o respeito entre as pessoas de realidades socioculturais diferentes.

Concluímos e constatamos a necessidade de investimentos em pesquisas que envolvam os falantes de línguas de herança, neste caso, o espanhol, residentes no Brasil a fim de traçar seus perfis, identificar suas necessidades, compreender o desenvolvimento de suas identidades e de suas relações afetivas com a LH.

\section{Referências bibliográficas}

AGÊNCIA BRASIL. Quem são e de onde vêm os 11 mil refugiados que estão no Brasil. 2019. Revista Exame. Disponível em: < https:/exame.com/brasil/quem-sao-e-de-onde-vem-os-11-milrefugiados-que-estao-no-brasil/> . Acesso em: 07 nov. 2019.

ALVAREZ, M. L. O. O falante de herança: à procura de sua identidade. In: ALVAREZ, M. L. O; GONÇALVES, L. O Mundo do Português e o Português no Mundo afora: especificidades, implicações e ações. Campinas, SP: Editora Pontes, 2016, p. 59-85.

BRASIL. Decreto $\mathbf{n}^{0}$ 849, de 25 de junho de 1993. Promulga os Protocolos I e II de 1977 adicionais às Convenções de Genebra de 1949, adotados em 10 de junho de 1977 pela Conferência Diplomática sobre a Reafirmação e o Desenvolvimento do Direito Internacional Humanitário aplicável aos Conflitos Armados. Disponível em: http://www.planalto.gov.br/ccivil_03/decreto/1990-1994/D0849.htm. Acesso: 19 nov. 2019.

BRASIL. Lei $\mathbf{n}^{\mathbf{0}}$ 13.445, de 24 de maio de 2017. Institui a Lei de Migração. Disponível em: http://www.planalto.gov.br/ccivil_03/_ato2015-2018/2017/lei/113445.htm. Acesso em: 20 nov. 2019.

DECLARACIÓN DE SALAMANCA. XV Cumbre Iberoamericana de Jefes de Estado y de Gobierno. Salamanca, Espanha. Octubre de 2005. Disponível em : https://www.segib.org/? summit=xv-cumbre-iberoamericana-salamanca-2005 Acesso em: 1 set. 2019.

FILLMORE, L. W. Loss of Family Languages: Should Educators Be Concerned? In: Theory into Practice, v. 39, $\mathrm{n}^{\mathrm{o}}$ 4, p. 203-210, Autumn, 2000. Disponível em: https://www.researchgate.net/publication/249901053_Loss_of_Family_Languages_Should_Educ ators_Be_Concerned. Acesso em: out. 2019. 
GALVÃO, M. C. B. O levantamento bibliográfico e a pesquisa científica. In: Laércio Joel Franco, Afonso Dinis Costa Passos. (Org.). Fundamentos de epidemiologia. 2ed. A. 398 ed. São Paulo: Manole, 2010, v. , p. -377. Disponível em: http://www2.eerp.usp.br/nepien/DisponibilizarArquivos/Levantamento_bibliografico_CristianeG alv.pdf. Acesso em: 01 ago. 2020.

GRAY, D. E. Pesquisa no mundo real. 2. ed. Porto Alegre: Penso, 2012. 488 p.

HE, A. W. The heart of heritage: Sociocultural dimensions of heritage language learning. Annual Review of Applied Linguistics, Cambrige, v.01, n. 20, p. 66-82, 2010.

LICO, A. L.; BORUCHOWSKI, I. D. Como manter e desenvolver o português como língua de herança: sugestões para quem mora fora do Brasil. Consulado-Geral do Brasil em Miami. Must University, 2016. Disponível em: https://sistemas.mre.gov.br/kitweb/datafiles/Montreal/ptbr/file/lingua $\% 20 \mathrm{de} \% 20$ heranca(1)(2).pdf . Acesso em: 22 nov. 2019.

MERCOSUL. Cartilha do Cidadão do MERCOSUL Edição 2010. Disponível em: < http://www.mercosul.gov.br/o-mercosul-na-vida-do-cidadao/a-cartilha-do-cidadao $>$ Acesso em: 28 out. 2019.

MONTRUL, S. Is the heritage language like a second language? EuroSLA, Yearbook, 2012. Disponível em: http://www.eurosla.org/Docs/Yearbook2012/Montrul.pdf Acesso em: out. 2019.

MORENO FERNÁNDEZ, F. Principios de Sociolingüística y Sociología del lenguaje. Barcelona: Ariel, $4^{\mathrm{a}}$ ed. jan. 2009. 381p.

OLIVEIRA, G. M. (Org.). Declaração universal dos direitos linguísticos. Campinas: Mercado da Letras, 2003.

RAJAGOPLAN, K. Política linguística: do que se trata, afinal? In: NICOLAIDES, C.; SILVA, K.A.; TILIO, R.; ROCHA, C. H. (Orgs). Política e Políticas Linguísticas. Campinas: Pontes/ALAB, 2013. p. 19-42.

TEIS, M. A. Escrita e letramento com alunos Avá-Guarani: aulas de reforço. 2007. 175f. Dissertação (Mestrado em Letras) - Programa de Pós-Graduação em Letras, Universidade Estadual do Oeste do Paraná, Cascavel, 2007.

TEMER, M. Brasil e Espanha: uma nova colaboração entre velhos amigos. Jornal El País. 2017. Disponível em: https://brasil.elpais.com/brasil/2017/04/22/actualidad/1492814836_462443.html. Acesso em: 13 nov. 2019.

UNESCO. Declaração Universal dos Direitos Linguísticos. 1996. Disponível em: http://www.dhnet.org.br/direitos/deconu/a_pdf/dec_universal_direitos_linguisticos.pdf. Acesso em: out. 2019. 
VALDÉS, G. Heritage language students: profiles and possibilities. In: PEYTON, J. K.; RANDARD, D.; McGINNIS, S. (Org.) Heritage languages in América: Preserving a national resource. Washington, DC: Center for Applied Linguistics, 2001. p. 37-80.

\section{Encuesta de estudios sobre el mantenimiento del español como lengua patrimonial en un contexto brasileño}

Resumen: En los últimos años, la discusión sobre el mantenimiento del español como lengua de herencia, en adelante ELH, ha sido objeto de un creciente debate en Lingüística Aplicada (MONTRUL, 2012; VALDÉS, 2001; WONG FILLMORE, 2000; MORENO FERNÁNDEZ, 2005). Podemos afirmar que, en general, los estudios sobre el mantenimiento de ELH se centran en las áreas de Lingüística y Sociolingüística y buscan identificar las razones por las cuales ocurren tales fenómenos. La mayor parte de la investigación sobre el tema en cuestión se realizó en los Estados Unidos, un país que alberga una gran cantidad de hispanohablantes, así como en Brasil. En este sentido, este estudio, que presenta resultados preliminares de una investigación más amplia en curso, tiene como objetivo realizar una encuesta de estudios sobre el mantenimiento de ELH en Brasil a través de una búsqueda bibliográfica en los portales de publicaciones periódicas Capes y Scielo, mapeo, desde en cierto modo, la producción académica brasileña sobre el tema en cuestión. Con los resultados obtenidos, se espera que otros investigadores de ELH en Brasil puedan beneficiarse de este estudio para justificar la importancia de la investigación sobre el mantenimiento del español como lengua de herencia en un contexto brasileño.

Palabras llave: inmigración; Lenguaje de herencia; El español como lengua patrimonial en Brasil.

\section{ANEXO 1 - PORTAL CAPES}

CARVALHO, M. A. Contribuições da sociolinguística ao ensino de português em comunidades bilíngues do Norte do Uruguai. Revista Pro-Posições, 2010, vol. 21, n.3, p. 4565 .

\section{ANEXO 2 - SCIELO}

FRITZEN, M. P. Ich spreche anders, aber das ist auch deutsch: línguas em conflito em uma escola rural localizada em zona de imigração no sul do Brasil. Revista Trabalhos em Linguística Aplicada, 2008, vol. 47, n.2.

FRITZEN, M. P.; EWALD, L. "Aqui somos protegidos pelas nossas quatro paredes. Aqui nós falamos Alemão": histórias de letramentos interculturais no Vale do Itajaí, SC. Revista Trabalhos em Linguística Aplicada, 2013, vol. 52, n. 2.

Gláuks: Revista de Letras e Artes-jan/jun. 2020 -Vol. 20, $N^{o} 1$ 
GLÁUKS

Gláuks: Revista de Letras e Artes-jan/jun. 2020 -Vol. 20, $N^{o} 1$ 